\title{
A Framework for Evaluating Tablet-based Educational Applications for Primary School Levels in Thailand
}

\author{
https://doi.org/10.3991/ijim.v12i5.9009 \\ Hsu Nang $\left.{ }^{\varpi}\right)$, Antony Harfield \\ Naresuan University, Phitsanulok, Thailand \\ nangh57@email.nu.ac.th
}

\begin{abstract}
When it comes to the use of mobile technology in the classroom, one of the major challenges for the teacher is finding suitable applications that appropriately match the topic of study. In most areas of education there are tools for evaluating teaching materials, but there are few tools for evaluating mobile technology in the classroom. The lack of evaluation methods means that for teachers, who are increasingly using tablets in the primary level classrooms, the results can be "hit or miss". The aim of the study is to propose and describe a new framework that enables primary school teachers to evaluate tablet-based games effectively. The proposed framework is adapted from the fourdimensional framework (FDF) and aims to support teachers in the choice of suitable tablet-based games to use in their classrooms that balance the essential aspects of student engagement (or playability) and learning achievement. A small case study is carried out based on the evaluation of 30 STEM applications on iPad. The proposed framework can predict the initial pitfalls of technical and design issues in applications before class use. The successfully evaluated applications are used for the experiment at primary school in Thailand. The improvement of students' learning skill, behavioral outcomes, and teachers' perspectives are not considered in this study.
\end{abstract}

Keywords-technology acceptance; mobile learning; schools; iPads

\section{$1 \quad$ Introduction}

The introduction of tablet-based educational applications in classrooms are supporting students to develop their academic ability in fun and engaging ways [1]. It could help learners to gain better understanding during their classes. While many educational applications are easily adapted by teachers for classroom use, it can be difficult to evaluate and select the suitable applications in a digital teaching context [2]. The right choice of application, the alignment to the lesson plan and curriculum, and the compatibility with existing technical equipment are important factors in delivering successful technology-based lessons [3]. With a good choice of application, students can benefit from active learning and extensive practice within a tablet-based learning environment [4]. Research has shown that tablets can be integrated with a 
variety of instructional teaching techniques, but that it can be difficult to achieve teaching goals and maintain students' attention in class [5]. In view of this, other experiments found that learners' likes, interests, and needs are critical to deploying iPads applications at schools [6]. One point that is in agreement is that a proper pedagogy and instructional activities are needed to integrate tablets at class [3].

A good educational application encourages the students to solve problems independently and increase their curiosity levels [7]. The high level performing students can level up into deeper learning concepts whereas low performing students can learn or refresh the basic concepts of subject [8]. The continuous new knowledge absorbing and self-center judgments in learning process are improved, potentially with little interference from teachers [9]. The use of mobile games in the education field is increasing and teachers are using them more regularly in the classroom [10]. It is continuously increased and $30 \%$ of classrooms are using games regularly on mobile devices [11]. Therefore, games have been shown to be an effective and popular teaching methods in the educational field. There are three reasons why teachers are using games in the classroom: a) games create personal motivation, b) they accommodate multiple learning styles and skills, and c) they provide interactive and decision making context [12]. It is a kind of a new learning situation can motivate learners in teaching and improve communication skill with friends [13].

\subsection{Difficulties in evaluating educational application}

The digital resources and applications are available as free to access for education use, where children are familiar with them. The effective use of portable technological devices at primary levels can promote student interest in literacy and numerical learning skills [14]. Nonetheless, teachers' knowledge, skills, attitude and perception about the role of technology tool and application is critical for the further development and implementing technology at class [15]. The difficulties in discovering and evaluating applications to use in classroom contexts are summarized as follows:

The quality of available applications on play stores are difficult to evaluate [16].

a) Applications to meet focus group's needs and can track the progress of learning are the common difficulties in finding applications [17].

b) Teachers are facing difficulties in integrating apps into class activities [18].

c) In order to create an effective teaching class, features of application and content are difficult to evaluate $[19,20]$.

d) $80 \%$ of teachers have difficulties in finding application to match with the lesson plan [11].

e) The suitability of tablet applications for a focus group and match with the content subject is difficult to evaluate [21].

f) The applications are difficult to evaluate that could enhance learning experiences [21].

Despite a large number of educational applications, there is little research available on providing ways to evaluate them, particularly in a classroom setting. While there are significant bodies of research on how to integrate learning and design principles to 
develop effective teaching and learning applications, there is less research focusing on how to evaluate good off-the-shelf educational applications for classroom use. The researches describe the common difficulties in balancing play-and-learn activity at class. The type of educational applications for children may not be suitable in a classroom setting - it may be too entertainment focused, not suitable for collaborative use or simply too loud or distracting for a classroom.

\section{Background of a new proposed framework}

The Four Dimensional Framework (FDF) was introduced by Freitas and Oliver to evaluate educational and simulation-based games. The framework gets its name from breaking the evaluation into four key areas or dimensions: Learner specifics, Pedagogy, Representation and Context. Each dimension describes the possible specifications might reflect the critical approaches to form technology aid learning activity as shown in Figure 1 [22].

\begin{tabular}{|l|l|}
\hline \multicolumn{2}{|l|}{ Four Dimensional Framework } \\
\hline Learner specifics & Pedagogy \\
\hline Profile & Associative \\
Role & Cognitive \\
Competencies & Social/Situative \\
\hline Representation & Context \\
\hline Fidelity & Environment \\
Interactivity & Access to learning \\
Immersion & Supporting resources \\
\hline
\end{tabular}

Fig. 1. Four Dimensional Framework

The research on FDF has discussed the reflection and efficacy on the practical use of game-and simulation-based learning. It is used as an evaluation tool through a "checklist" in terms of analyzing features and misleading concepts in games. FDF is highly suited to simulation-based games, which highlighted the requirements of games-and-simulation play activity and initial pitfalls in formal learning context. The continuous re-evaluations process is mapping to identify gaps between learners and design issues to support effective learning outcomes. The findings are validated for the future parameters to design relating to games-and-simulation application. The remainder of this paper focusses on the adapting the successful parts of FDF to tabletbased educational applications and modifying it where required.

The authors propose a Four Dimensional Framework for Tablet-based Educational Applications (FDF-TEA) which is adapted from FDF and focusses on supporting primary school teachers to create tablet-based learning activities in their classrooms. FDF-TEA targets learning situations that are different from FDF in 3 areas, as shown in Table 1. Where FDF focusses on simulation games and virtual worlds on a computer-based platform (e.g. PC), the FDF-TEA evaluates educational applications on tablets. The target group of FDF is people facilitating college and lifelong learners, but FDF-TEA is targeting the facilitators of primary school education. The objective 
is helping to evaluate the quality of education applications to create efficient and effective teaching environment.

Table 1. Target group differences between FDF and FDF-TEA framework

\begin{tabular}{|l|l|l|}
\hline \multicolumn{1}{|c|}{ Difference } & \multicolumn{1}{|c|}{ FDF } & \multicolumn{1}{c|}{ FDF-TEA } \\
\hline Type of software & $\begin{array}{l}\text { Simulation, games and } \\
\text { virtual worlds. }\end{array}$ & Educational applications. \\
\hline Platform & Computer-based. & Tablet-based. \\
\hline Target learners & College and lifelong learners. & Primary school learners. \\
\hline
\end{tabular}

\section{$2.1 \quad$ FDF-TEA framework}

The change in target group warrants a modification to the detailed of dimensions in FDF. The FDF-TEA will cover four perspectives similar to FDF. Three of the dimensions (learner specifics, pedagogy, and context) will be closely related to the original framework with minor changes to take account of changes in the target group and technology. Therefore, the proposed framework has equivalent criterion in "Learner specifics", "Pedagogy" and "Context" dimension. The existing criterion in "Representation" dimension of FDF is not well aligned with tablet-based applications' features because of the changes in type of software and platform.

The simulation-based virtual world education games for primary school children will not consider in this proposed framework. Most tablet-based educational applications have simple presentation and features to support learners in performing tasks. Children are able to progress and control of their play on tablet-based application [23]. Feedbacks and scaffolding are important in applications for young learners [24]. The effective use of feedbacks make less confuse, prevent deviation from goal, and give directions to accomplish task [25]. Presentation, styles of the application, and interactivity or feedbacks criteria are presented to match the background context of this study. Those criteria are assumed as needed in "Application representation" dimension.

\begin{tabular}{|l|l|}
\hline FDF-TEA Framework & \\
\hline Learner specifics & Pedagogy \\
\hline Profile & Associative \\
Role & Cognitive \\
Competencies & Social/Situative \\
\hline Application representation & Context \\
\hline $\begin{array}{l}\text { Presentation } \\
\text { Styles of the application }\end{array}$ & Environment \\
Interactivity or Feedbacks & Access to learning \\
\hline
\end{tabular}

Fig. 2. Proposed FDF-TEA framework 
Figure 2 illustrates the proposed FDF-TEA framework especially focuses on play activity via tablets for primary school students. There are four parts in this framework:

a) Learner specifics: the profile of focus group in tablet-based teaching activity is described in the first dimension. The purpose is acquiring the present learning level of a focus group before tablet-based teaching activity. It could be advantage on delivering lessons.

b) Pedagogy: the second dimension discusses which education theories would be applied at technology-based teaching class. The reason is that the features of application and content are difficult to evaluate the efficient and effective teaching process.

c) Application representation: the third dimension is carefully reviewed on application representation. The objective is evaluating the inappropriate use of game features such as achievements, rewards, level-up descriptions, and feedbacks in application.

d) Context: the fourth dimension is to estimate technical requirements in setting up tablet-based teaching activity. The reason is to minimize technical problems in order to less frustrate in teaching at class.

\section{Method}

The tablet-based 30 educational STEM applications from the App Store are searched and evaluated by using the proposed FDF-TEA framework and checklists. Authors played the role of the educators whose task were to evaluate the activities using FDF-TEA. The successfully evaluated applications are accessed by Primary-3 and Primary-4 students at Wat Dhammakasat Primary School in the Lower Northern Part of Thailand. A variety of applications and teaching pedagogies were applied during the experiments at class. The study was carried out over eight weeks for one hour per week for each level in early 2015.

The limitation of this study is only focused on the evaluation methods, STEM education applications and how does FDF-TEA framework can evaluate applications to have an operative teaching environment. Student's learning and behavioral outcomes might not be considered in this study.

\subsection{FDF-TEA process cycle}

Researchers have followed the FDF-TEA process cycle is shown in figure 3, was used in carrying out an initial experiment at school. The process cycle is helped educators in preparing the operative learning environment with tablet at class. FDF-TEA framework and checklists are comprised in this process cycle.

The process cycle is composed of 6 steps that teacher should follow in creating tablet-based teaching at classroom. 


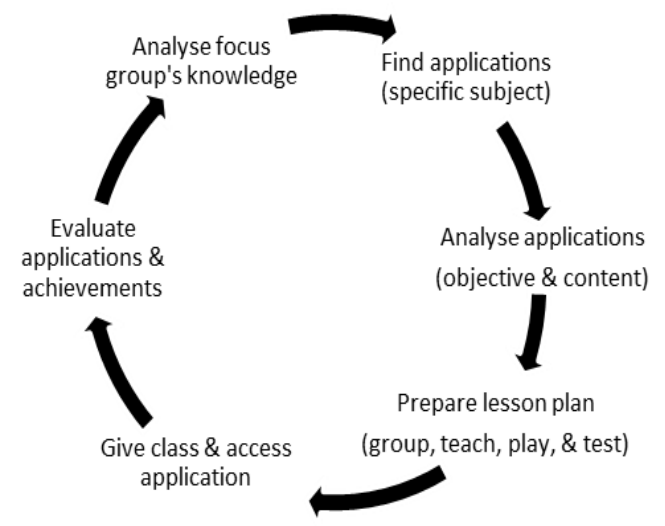

Fig. 3. The process cycle of FDF-TEA framework

a) Analyze focus group's knowledge: Teachers must know the background knowledge of focus group in certain subjects.

b) Find applications: Teaching objective, lessons, and learners' need are the general critical criteria in finding applications (i.e. FDF-TEA framework is used) in this step.

c) Analyze applications: In this process, FDF-TEA evaluation checklist is used for choosing applications, which has described in the following session.

d) Prepare lesson plan: Plans for teaching time, number of students per group, applications, and teaching method will take place at class. The pre and post assessments should be prepared if class teacher would like to know the improvement of student learning performance on tablets.

e) Give class and access applications: Teachers execute the lesson.

f) Evaluate applications and achievements: Application presentation is evaluated by using FDF-TEA. The evaluation of students' achievements in learning is depended on the teacher's opinion. The outputs are the next carefully consideration of choosing tablet-based applications.

The objective of presenting the process cycle is sharing knowledge to primary school teachers to carry out an active and effective teaching activity with tablet.

\subsection{Practical use of FDF-TEA checklist and result}

FDF-TEA framework and its checklist is a practical tool for teachers to do their own evaluations. Similar to the original FDF checklist, it consists a set of closed and open-ended questions as described in table 2. The first three dimensions have the same content as original FDF and the last dimension has been replaced by questionnaires on the educational applications' design and presentation. The purpose of wellprepared FDF-TEA checklist is accruing information on how the tablet-based education application supports for teaching. The purpose is to provide consistent and completeness information to make accurate decisions in selecting applications. There are 
some reasons why we did not modify learner specifics, pedagogic consideration, and context dimension.

a) The focus group is a primary actor of tablet-based teaching activity. Their profile is critical aspect to know before creating an activity.

b) The careful thought on learning pedagogies is critical because it would be varied on the objective of teaching and activity.

c) The possible requirements in various contexts such as extra teaching resources and technical requirements to bring an effective teaching environment.

Most questions in FDF-TEA checklists are helping to figure out the prerequisite in potential difficulties. The original framework and the proposed FDF-TEA framework have the same fundamental focus and encouraging having learning on applications. Nonetheless, the context of proposed framework is particularly emphasized on tablet applications. The questions for application representation dimension are modified to match with the proposed framework. All questions are focused on application representation. The evaluation results of some educational applications are presented in table 3 , 4, and 5 .

Table 2. Checklist of FDF-TEA for evaluating the use of tablet-based education applications

1. Learner specification

Who is the learner?

What is their background and learning history?

What are the learning styles/preferences?

Who is the learner group?

How can the learner or learner group are best supported?

In what ways are the groups working together (e.g. singly, partially in groups) and what collaborative approaches could support this?

\section{Pedagogic considerations}

Which pedagogic models and approaches are being used?

Which pedagogic models and approaches might be the most effective?

What are the curricula objectives?

What are the learning outcomes?

What are the learning activities?

How can the learning activities and outcomes be achieved through existing games or simulations?

How can the learning activities and outcomes be achieved through specially developed software (e.g.

embedding into lesson plans)?

How can briefing/debriefing be used to reinforce learning outcomes?

\section{Context}

What is the context for learning (e.g. school, home, and combination of several)?

Does the context affect learning (e.g. level of resources, accessibility, and technical support)?

How can links be made between context and practice?

\section{Application representation}

What tablet-based education game is being used?

Which part of the game is being used?

What is the style of the game (e.g. goal-oriented, open-ended, and scenario-based)?

What metaphors (abstract or concrete) of realism are used?

Are there any scaffolding (e.g. tutorial, instruction) provided by game?

What rewards (achievements, scores, time taken, and level-up) are given to describe player's performances? 
Table 3. The evaluation result of Quick Math+

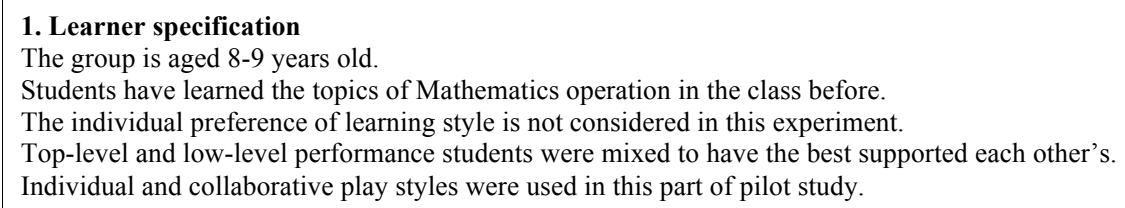

\section{Pedagogic considerations}

Most activities in Quick Math+ game are various kinds of calculation and pattern recognition. In such case, problem solving theory is applied.

"Learning by doing" method is applied in the experiment of tablet-based learning activity.

Learning outcomes are achieved by solving the arithmetic problems.

Achievements and level-up descriptions are reinforcing to take the next level of learning challenges.

\section{Context}

The game is used in the classroom of 20 students.

It is an offline tablet-based game supports learning in mathematics.

The aim of Quick Math+ is to test arithmetic skills such as memory, pattern recognition, logic, and estimation ability.

\section{Application representation}

Quick Math+ tablet-based offline game is used in this study.

All of the mini games in Quick Math+ were used.

The metaphor of game presentation is simple and easy to understand for students.

Students can write answer on the screen, which is similar as worksheet exercise.

Not like other games, players need to participate in animation tutorial.

Different kinds of rewards (e.g. stars and scores) are used to measure player's achievements.

Level-up animation encourages players for better achievements.

Table 3 describes the overall evaluated result of Quick Math+. The objective is helping to upgrade their arithmetic skills such as pattern recognition, logic, and estimation ability. A challenging step-up question set such as negative numbers, order of operation questions, and negative numbers of math concepts for high-level performance students are used in it. Moreover, low-level learning ability students can practice basic concept of mathematics. The application is suitable for 8 years old and above primary school children.

The evaluation described animation tutorial concept as "Pattern recognition" tutorial might be difficult to practice before play time. Moreover, it might be difficult to understand the concept and adapt to access application. Quick Math+ provides gesture feature for answering given questions. The bottom-line highlighted game representation could lead misunderstanding the abstraction of game.

"Fun English" is an offline game where the evaluation result is illustrated in table 4. The different categories of vocabularies are composed in it. The realism metaphors are applied in different styles in each mini-game. Feeding fruit to the mouse is an example of concrete metaphor scenario. The application design is fun-based learning activity on realism, which is contrasting from other application design. The objective is helping the development of cognitive and motor skills of aged 3-10. 
Paper-A Framework for Evaluating Tablet-based Educational Applications for Primary School Levels...

Table 4. The evaluation result of Fun English

\section{Learner specification}

Fun English is aiming for aged 3-10 and used as supplement teaching tool of learning second language. Students are weak knowledge in vocabularies and pronunciations.

To be a best support, an assistant taught and explained the meaning of vocabularies to all students before play game.

Students played individually in order to be more concentrated in linguistic learning.

\section{Pedagogic considerations}

Goal-oriented concept can be seen in this game scenario (e.g. learn new vocabularies through feeding mouse).

Zone of proximal development method is applied to improve the different level of individual learning skill.

The experiment created two parts of learning activities: 10 minutes teaching session and 30 minutes play session.

The effective learning outcome is directed from the animation feedback in each activity.

\section{Context}

Primary 3 and 4 students played Fun English in the pilot study.

The offline game assists for learning four skills in English.

The objective is teaching English vocabularies and pronunciations in different categories.

\section{Application representation}

Most of the mini games in Fun English are used in this study.

Concrete metaphor realisms are found in it (e.g. seeking objects, feeding animals, painting objects and different kinds of).

The style of the game is goal-oriented where players have to accomplish certain given tasks under specific limitations.

Time and sound are commonly used as amongst mini games to measure player's performances.

Not like the mathematics application, the game does not provide tutorial or instruction but good feedbacks and simple presentation make easy to play application. It is suitable for any ages in learning English vocabulary as second language. The overall evaluation pointed the relevant use of game features and presentation might easy to attract learners' interest in learning.

Table 5 describes the evaluation result of 100 Words application. The significant feature is providing "customize learning mode (sound, image, and pattern)" in game. Teachers can adjust the learning as upon the individual weaknesses mode (e.g. a student's need to practice more in listening skill). The disadvantage is that player must play at least one time online access before offline. Teaching vocabularies in several context of learning is an objective of 100 Words game. The game design is simple and similar with "flash card" presentation. The different play modes can be chosen as learner's requirement.

The application design might be familiar with learner but it is difficult to assume the game features could reinforce for learning motivation. Nevertheless, the result represented students can more emphasize on different learning process because of simple design. In order to compare with Fun English application, it provides good audio for listening practice. Thus, students were less frustrated in using application. 
Paper-A Framework for Evaluating Tablet-based Educational Applications for Primary School Levels...

Table 5. The evaluation result of 100 Words

\section{Learner specification}

The game was used with 8-9 years old children.

Students are weak in matching picture and letters, and listening skill.

To be a better supportive learning activity, assistants helped players if they could not overcome level or did not well how to perform activities.

Learners played independently but allowed them to ask question or discussed about game freely.

\section{Pedagogic considerations}

The purpose of 100 Words is to improve young student's recognition skill in new vocabularies.

The objective is teaching vocabularies in several contexts to enhance listening and pattern recognition.

10 minutes of scaffolding teaching method is applied before play activity.

Subject teacher taught words and picture to remember before students play games on tablets.

In this game, we could say learning outcomes and debriefing are directed from the total scores of game.

\section{Context}

100 Words is played by 20 primary school children in the activity room.

It is a one-time online play game before offline, have various kind of activities (sound, image and multiple choices).

It supports for learning vocabularies to improve listen and recognition skills in English.

\section{Application representation}

A part of 100 Words, "Family (sound and image categories)" is played by young students.

Some features are similar to the traditional "card game" presentation.

The presentation of game style is easy to play for children. Thus, there is no explanation or tutorial part of how to play game is not described in it.

Scores and animation feedbacks indicated the right or wrong answer of each question.

\section{$4 \quad$ Finding}

The study shows the initial difficulties in bring tablet and applications to class. Although many researches have shown mobile teaching methods and resources could effectively support student learning skills. The major difficulty is evaluating and selecting suitable applications to use in class. The study illustrated that there are many factors to consider organizing an activity within the context diversity, including both pedagogy and different levels of knowledge. The proposed framework evaluates the quality of each app, which could help to have a better tablet-based teaching. The possible pitfalls in representation and initial requirements from the various perspectives are found out as the potential challenges. Despite the challenges, findings could be helpful in efficiently manage and monitor technology class. The suggested applications would be both accepted and enjoyed by subject teacher and class.

A scenario will explain how searching applications can be supported by FDF-TEA framework. A teacher is looking for an English subject applications to use in the classrooms. The proposed framework illustrates the overall reviews on each application. The framework guides teachers through selecting the suitable applications and supports for the class or activity. Both applications of "Fun English" and "100 Words" have the general objective as teaching vocabularies. They represent contents in different teaching styles by using different application's features such as metaphor, graphics, and feedback. The framework figures out the possible features in application 
which might deviate from achieving goal and technical issues. Such thus, teachers have to choose the most suitable applications to meet the teaching objectives, class activity, and learners' requirements.

The proposed framework represents the strengths and weaknesses of each application but it could not recommend which one is better. "Fun English" applied realism scenario to attract learners' interest in learning. The advantage from technical perspective, it provides online and offline play after downloaded application. The various types of learning activities (i.e. spelling, listening, and etc.) are formed in each application. The disadvantage of application is an audio problem and students might require headphones if an activity is to practice listening skill at class. "100 Words" application design does not provide the background music. It might be helping students to more emphasize in learning vocabularies. The strength of game is letting students to practice English vocabularies as their preferences. However, technical problems and game features might inconvenience for leaners.

In order to compare applications from different subjects such as Mathematics and English applications, both of them have the different content representations. Quick Math + application design is minimalistic and esthetics. Nonetheless, the animation tutorial with player involvement might confuse in delivering play procedure. English subject applications are applied concrete metaphor, complex graphics design, and omitted tutorial parts. Application designs could be relied on the objectives of the application, application designers or publishers. One of the examples is that the objective of mathematics application is how to solve and think the mathematics problem logically while English applications are allowing players to learn at their own paces. Hence, the application representations are not the same even though using same game features. However, both Mathematics and English applications allow students to have more practical experience in learning.

The proposed framework shows how to apply FDF-TEA framework in three main areas: evaluating applications, facilitating class activities, and estimating possible teaching achievements via applications. The evaluations demonstrated linguistic games have comprehensible and simple interface while mathematics game has the ambiguous animation tutorial. The unexpected technical problems are acknowledged before carrying out teaching activity at class. On the other hands, it could help in educational application development process. The following facts represent how FDF-TEA could help in evaluation or development of tablet-based education application.

d) The possible initial technical problems are identified before teaching at different contexts.

e) The adaptable scaffolding part or short description of application is required for learners.

f) The distinct features of app and a wide availability of content can reduce teacher's stress in choosing application.

g) The apply pedagogy and application representation are relying on each other.

FDF-TEA framework serves as guidelines to help in choosing applications before occupying technology-based teaching at class. It could apply in the development of 
Paper-A Framework for Evaluating Tablet-based Educational Applications for Primary School Levels...

designing educational application process. Moreover, FDF-TEA process guides how to apply tablet technology and application inside the classroom.

\section{Conclusion}

While use of tablet applications in the classroom is becoming common, finding and evaluating applications to match the curriculum is a significant challenge for educators. The FDF-TEA framework is proposed as an evaluation tool for highlighting the overall positive and negative features of applications within specific classroom contexts. The tablet-based educational applications are analyzed to know would it be a greater use at mobile teaching class. The framework demonstrates which application could help student in better learning than comparing with other applications. The study illustrates the careful analyze and choose applications to minimize possible problems at class. The bottom-line of study represents teacher should have the clear objective and preference in teaching styles before searching applications. The needs of specific focus group, teaching context and apply teaching theories are the other basic requirements to know to form tablet-based teaching. Hence, teachers have to know obviously what outcomes they would like to have after teaching with computational devices. The following statements present how FDF-TEA helps in searching relevant applications for classroom use.

a) FDF-TEA describes the suitability of an application before and after used in a classroom.

b) The proposed framework can help to improve future tablet-based activities.

c) FDF-TEA process guides how to setup tablet-based teaching on applications.

d) The framework illustrates the distinct features of each application which might lead positive or negative impacts in teaching.

FDF-TEA helps to create a quality of tablet-teaching design, evaluates the quality of previous form of teaching. It shows the requirements to form a better teaching situation. The requirement of mobile teaching activity is determined before assigning task to class. At the initial stage, the proposed framework describes that the application is matched with the objectives of teaching and curricula's content. The results of evaluations describe the potential benefits of applications for the primary school level. Teachers can know which application is offering fun, match with criteria of a teaching environment and empower learners' learning experiences. The classroom teaching activity might get an active and teachers might get new ideas for how to integrate tablet in class. The evaluations show teachers how to evaluate and select applications to have an operative teaching activity. Furthermore, it determines the quality of new form of application-based teaching via tablets.

The future experiments will carry with more educational games on STEM subjects at different primary schools. In order to be easy applied FDF-TEA framework at class, "Apps4Youth" web-based system is going to implement under the guidelines of the framework. The system will allow educators to contribute their own evaluations of applications to the tablet teaching community. It would be knowledge sharing system 
for primary school teachers for the information of using tablet educational games at class. The survey will be undertaken at primary schools in Thailand to explore how it would be useful for teachers.

\section{References}

[1] B. Siemieniecki and K. Majewska, "Pedagogical premises of the use of tablets in the teaching process," 2015.

[2] E. Geist, "Using Tablet Computers," YC: Young Children, vol. 69, pp. 58-63, 2014.

[3] J. Q. Montoya, G. D. H. Rojas, and F. A. O. Dussan, "Influence of digital tablets on the students' learning within a program strengthening teachers' pedagogical practices," in Interactive Mobile Communication, Technologies and Learning (IMCL), 2016 International Conference on, 2016, pp. 55-57.

[4] B. Cukurbasi, O. Isbulan, and M. Kiyici, Acceptance of Educational Use of Tablet Computers: A Critical View Of The FATIH Project, 2016.

[5] H. J. Kim and H. Kim, "Investigating teachers' pedagogical experiences with tablet integration in Korean rural schools," The Asia-Pacific Education Researcher, vol. 26, pp. 107116, 2017. https://doi.org/10.1007/s40299-017-0331-8

[6] D. P. O. Auquilla and G. E. H. Urgilès, "The use of iPad and applications for English Language Education," Theory and Practice in Language Studies, vol. 7, p. 709, 2017. https://doi.org/10.17507/tpls.0709.01

[7] M. N. Giannakos, "Enjoy and learn with educational games: Examining factors affecting learning performance," Computers \& Education, vol. 68, pp. 429-439, 2013. https://doi.org/10.1016/j.compedu.2013.06.005

[8] L. P. Flannery, B. Silverman, E. R. Kazakoff, M. U. Bers, P. Bontá, and M. Resnick, "Designing ScratchJr: Support for early childhood learning through computer programming," in Proceedings of the 12th International Conference on Interaction Design and Children, 2013, pp. 1-10. https://doi.org/10.1145/2485760.2485785

[9] I. Kovačević, M. Minović, M. Milovanović, P. O. de Pablos, and D. Starčević, "Motivational aspects of different learning contexts: "My mom won't let me play this game..."," Computers in Human Behavior, vol. 29, pp. 354-363, 2013/03/01/ 2013.

[10] P. Moreno-Ger, D. Burgos, I. Martínez-Ortiz, J. L. Sierra, and B. Fernández-Manjón, "Educational game design for online education," Computers in Human Behavior, vol. 24, pp. 2530-2540, 2008/09/17/2008.

[11] L. M. Takeuchi and S. Vaala, "Level up Learning: A National Survey on Teaching with Digital Games," Joan Ganz Cooney Center, 2014.

[12] M. Kebritchi, "Examining the pedagogical foundations of modern educational computer games," Computers \& Education, vol. 51, pp. 1729-1743, 2008. https://doi.org/10.1016/ j.compedu.2008.05.004

[13] K. Facer, "Children's Out of School Uses of Computers," A report for the InterActive Education Project, available on www. interactiveeducation. ac. uk/school. pdf, 2001.

[14] B. Haßler, L. Major, and S. Hennessy, "Tablet use in schools: a critical review of the evidence for learning outcomes," Journal of Computer Assisted Learning, vol. 32, pp. 139156, 2016. https://doi.org/10.1111/jcal.12123

[15] K. F. Hew and T. Brush, "Integrating technology into K-12 teaching and learning: Current knowledge gaps and recommendations for future research," Educational technology research and development, vol. 55, pp. 223-252, 2007. https://doi.org/10.1007/s11423-0069022-5 
Paper-A Framework for Evaluating Tablet-based Educational Applications for Primary School Levels...

[16] M. Levine, "Reading with young children: Something old and something new?," ed: Joan Ganz Cooney Center. Retrieved from http://joanganzcooneycenter. org/Cooney-CenterBlog-270. html, 2012.

[17] C. Blackwell, "Teacher practices with mobile technology integrating tablet computers into the early childhood classroom," in Advances in Communications and Media Research, ed: Nova Science Publishers, Inc., 2014.

[18] D. Ifenthaler and V. Schweinbenz, "The acceptance of Tablet-PCs in classroom instruction: The teachers' perspectives," Computers in human behavior, vol. 29, pp. 525-534, 2013. https://doi.org/10.1016/j.chb.2012.11.004

[19] N. Kucirkova, "iPads in early education: separating assumptions and evidence," Frontiers in psychology, vol. 5, p. 715, 2014. https://doi.org/10.3389/fpsyg.2014.00715

[20] G. Falloon, "Young students using iPads: App design and content influences on their learning pathways," Computers \& Education, vol. 68, pp. 505-521, 2013. https://doi.org/10.1016/j.compedu.2013.06.006

[21] W. Clark and R. Luckin, "iPads in the Classroom," What The Research Says, 2013.

[22] S. De Freitas and M. Oliver, "How can exploratory learning with games and simulations within the curriculum be most effectively evaluated?," Computers \& education, vol. 46, pp. 249-264, 2006. https://doi.org/10.1016/j.compedu.2005.11.007

[23] I. Verenikina, J. Herrington, R. Peterson, and J. Mantei, "The affordances and limitations of computers for play in early childhood," in EdMedia: World Conference on Educational Media and Technology, 2008, pp. 3091-3100.

[24] D. J. Nicol and D. Macfarlane-Dick, "Formative assessment and self-regulated learning: A model and seven principles of good feedback practice," Studies in higher education, vol. 31, pp. 199-218, 2006. https://doi.org/10.1080/03075070600572090

[25] M. Van Reeuwijk, "School algebra struggle, what about algebra computer games," in 10th International Congress on Mathematical Education (ICME), Roskilde University, Kopenhagen, Denmark, 2004.

\section{Authors}

Hsu Nang is with the Department of Computer Science and Information Technology, Faculty of Science, Naresuan University, Phitsanulok, Thailand (nangh57 (a)email.nu.ac.th).

Antony Harfield is with the Department of Computer Science and Information Technology, Faculty of Science, Naresuan University, Phitsanulok, Thailand (antonyh@nu.ac.th).

Article submitted 09 June 2018. Resubmitted 19 July 2018. Final acceptance 19 July 2018. Final version published as submitted by the authors. 